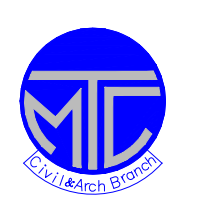

ICCAE

Military Technical College

Kobry Elkobbah,

Cairo, Egypt 7th International Conference

On Civil \& Architecture

Engineering

\title{
FINITE ELEMENT PROCEDURE FOR MODELING SOIL- STRUCTURE-FOUNDATION INTERACTION IN BUILDING SEISMIC DAMAGE RESPONSE
}

\section{ABSTRACT}

ISMAIL MOHAMED KAMAL*

A finite element based computational procedure is presented for soil-structure interaction modelling in building due to seismic damage response. Attention is focused on a combination of contact surfaces at the soil-foundation interface, nonlinear soil material response, and infinite elements as transmitting boundary conditions. A rationale for efficient mesh design is offered for the detailed building/foundation/soil system model based on computational wave propagation studies using infinite elements.

To evaluate the performance of the proposed procedure for handling SSI, a complete comparison between four models for a 3-story office building were performed. The models classified as one fixed base model without any effect of soil, second with the conventional treatment of the foundation and soil as discrete linear springs, the third incorporating the proposed procedure with elastic properties of soil, and the fourth proposed procedure with non-linear properties of soil.

This evaluation was based on the capability of the model to capture the different column damage indices. These indices are: acceleration time history, the floors drift ratio, and moment-curvature plot for the column. The strategy adopted for the analysis is performed a seismic dynamic analysis for the four models by using the general purpose finite element code ABAQUS. Conclusions that can help in clearing and analyze the system response were cleared out.

\section{KEY WORDS}

3-D Simulations; Soil-Structure Interaction; Infinite Elements; Nonlinear Contact Surface; Seismic Dynamic Analysis.

\footnotetext{
* Permanent staff (PhD) - Civil Eng. Department, Military Technical Collage - Cairo, EGYPT
} 


\section{INTRODUCTION}

Case studies of structure seismic response have highlighted the importance of interaction between structure, foundations and soil deposits. A structure with finite dimensions is embedded in deformable soil of infinite dimensions. The time-dependent load can either act directly on the structure, arising for instance from rotating machines or be introduced into the dynamic system through incident waves as from earthquakes.

In order to model this problem using computational simulation procedures, two main difficulties should be taken into consideration:

\section{Transmitting Boundary Conditions}

The most common analytical Soil-Structure Interaction models are based on the assumptions that the soil domain may be represented by an elastic half space and that dashpots may be used to represent the transmitting boundary conditions [1]. These boundary conditions are required to model both radiation damping of the foundation motion as waves propagate outward into the infinite domain and to prevent reflections back into the foundation from any artificially introduced finite domain of the half-space. A recent study shows some disadvantages for these dashpots especially with large computational models [2].

\section{Soil / Structure Interface}

A number of recent research studies have provided insight into the seismic response characteristics of structures. Application of system identification techniques to measure earthquake response data for structures has indicated that structure foundations and the surrounding soil constitute a strongly coupled system. The dynamic behavior of the structure foundations and the surrounding soil has a first order influence on the dynamic response of the structure. Analysis of measured strong motion response data has also indicated that local nonlinear behavior of soil can result in significant nonlinear global behavior of the entire system, even when the structure remains linear. This local nonlinear behavior should be taken into consideration in any modeling procedure.

\section{PROPOSED FE MODELING PROCEDURE}

Based on a preliminary study for the two main problems of the SSI modeling, the following FE model has been developed by FE code ABAQUS [3] for a typical three-story reinforced concrete building.

\section{Specifications of the Building}

A three-story office building located in north Mississippi having out side dimensions of $24 \mathrm{~m} \times 12$ $\mathrm{m}$ and consisting of three panels of $8 \mathrm{~m}$; by two bays with panels of $6 \mathrm{~m}$ is to be designed in accordance with the Standard Building Code [4].

\section{Building SSI Model}


ABAQUS FE models were developed as shown in Fig. 1 using a Patran graphical user interface for the building and the surrounding geology. The mesh for the complete model has 11155 elements. For the sake of convenience in modeling, the model is broadly classified into the following groups:

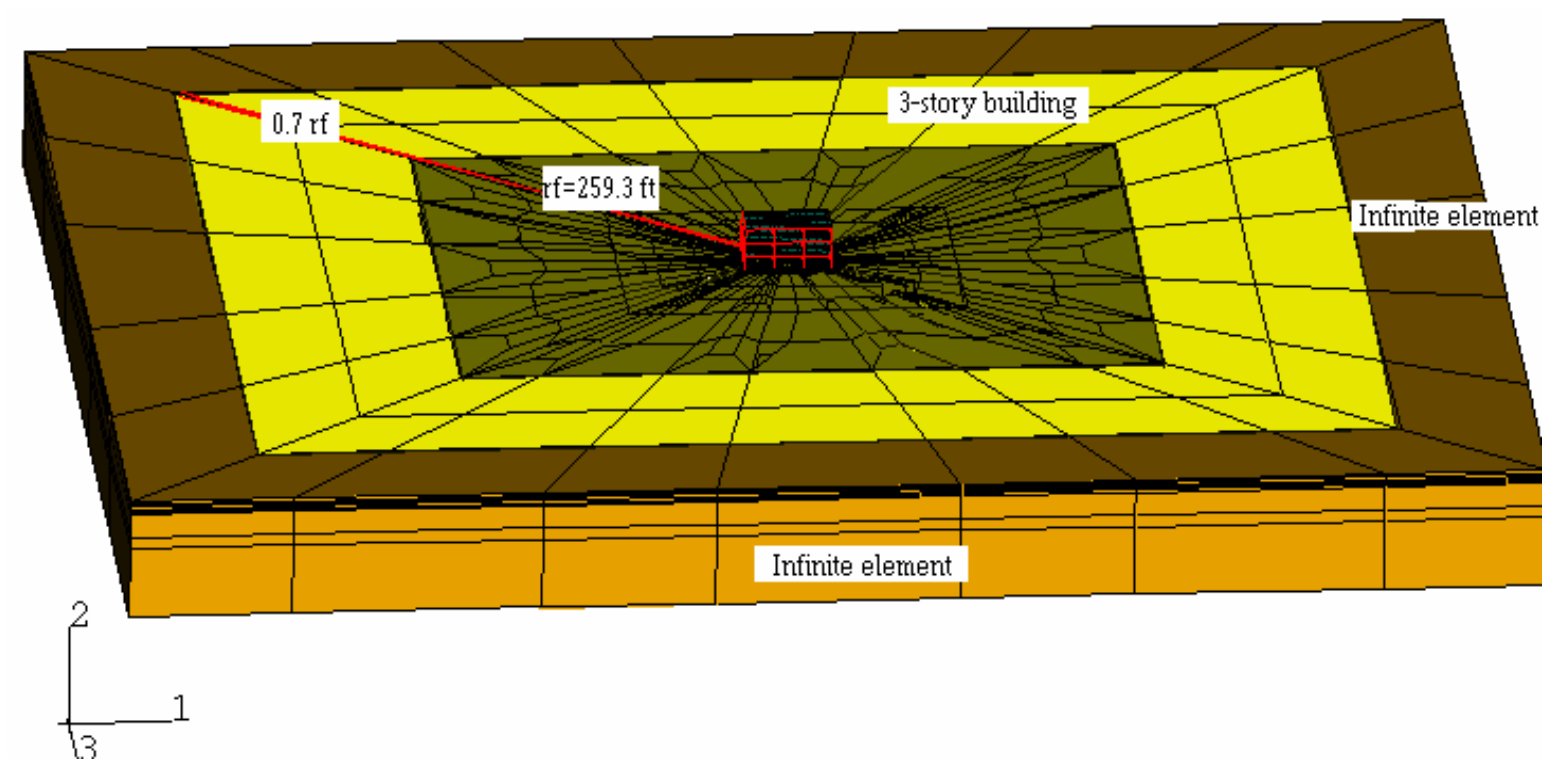

Fig.1 3-D Detailed FE Model of 3-Story Building

\section{Floor Slabs:}

The floor slabs, which are $0.2 \mathrm{~m}$ in thick, are modeled using four nodded bending elements. The slab mesh is finer near the edges and courser in the center.

\section{Beams and Columns}

The beams and columns are modeled with beam element, which has 6 degrees of freedom per node. Due to the fact that 1-D modeling is used for the columns and beams, there is a difference in elevation between the tops of the columns and the beams. Hence a fictitious beam-column element is used to provide a rigid connection between them. These elements are given in-plane flexural rigidity values about ten times of the topmost elements of the columns to more closely resemble the stiffness of the haunches.

\section{Footings}

All the footings in the building are isolated reinforced concrete footings, each footing was modeled by eight 3-D rectangular prism elements in two layers each layer is four elements.

\section{Soil}

The soil underneath and around the building is modeled using 3-D rectangular prism elements. The depth of the modeled soil is $35 \mathrm{~m}$ [5] with three layers. The properties of the soil layers and the equivalent one are as shown in Table 1.

Table 1 Soil Properties 


\begin{tabular}{|c||c|c|c|c|c||}
\hline $\begin{array}{c}\text { Soil } \\
\text { Layer }\end{array}$ & $\begin{array}{c}\text { Thickness } \\
(\mathbf{m})\end{array}$ & $\begin{array}{c}\text { Density }(\gamma) \\
\left(\mathbf{t} / \mathbf{m}^{\mathbf{3}}\right)\end{array}$ & $\begin{array}{c}\text { Shear Wave } \\
\text { Velocity }\left(\mathbf{V}_{\mathbf{s}}\right) \\
(\mathbf{m} / \mathbf{s})\end{array}$ & $\begin{array}{c}\text { Poisson' } \\
\text { Ratio (v) }\end{array}$ & $\begin{array}{c}\text { Elastic } \\
\text { Modulus (E) } \\
\left(\mathbf{t} / \mathbf{m}^{2}\right)\end{array}$ \\
\hline \hline 1 & 10 & 1.922 & 166.5 & 0.33 & 9466.34 \\
\hline 2 & 5 & 1.768 & 296.1 & 0.317 & 44213.20 \\
\hline 3 & 20 & 1.922 & 370.0 & 0.35 & 73344.73 \\
\hline $\begin{array}{c}\text { Equiv. } \\
\text { layer }\end{array}$ & $\mathbf{3 5}$ & $\mathbf{1 . 9 2 1}$ & $\mathbf{2 6 5 . 6}$ & $\mathbf{0 . 3 4 1}$ & $\mathbf{3 5 9 1 5 . 9 0}$ \\
\hline
\end{tabular}

\section{Soil-Structure Interface}

Based on a preliminary study has been performed [2], the contact-surface approach has been used to model the soil-structure interface, the footing and the surrounding soil were modeled as master and slave sub-models as in Fig.2. The mesh of the footing and the soil are different. Based on the soil properties a friction coefficient of 0.2 has been applied between the soil and the footing. Very rigid fictitious four nodded shell elements are used at the middle of the footing thickness connected to the column to provide a rigid connection between the column and the footing.

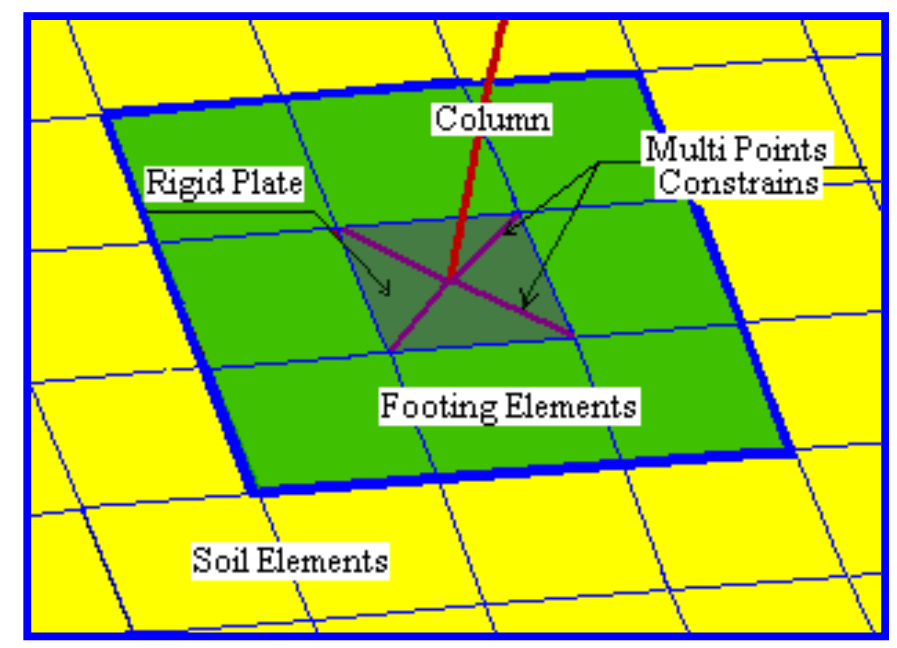

Fig.2 Detail of SSI Modeling Procedure

\section{Infinite Elements}

Based on the properties of the equivalent soil layer, the far filed radius [1] of the model is $79 \mathrm{~m}$. According to the results of the preliminary study and in order to have a well performance from the infinite elements as transmitting boundary conditions, soil should be modeled up to $134 \mathrm{~m}$ from the center of the building in the all directions.

LINEAR SPRINGS AND FIXED BASE MODELS 


\section{Linear Springs Model}

According to FEMA guidelines [5], the SSI analysis can be performed for the structure seismic analysis by replacing the foundation and the soil by six linear springs, three for the translation degrees of freedom and three for the rotation ones as presented in Fig. 3. The Linear spring coefficients depend on the geometry of the footing and soil properties. Another model with FEMA linear springs has been developed for the same building. Table 2 presents the calculated spring stiffnesses, adopted in this study.

\section{Fixed base Model}

To study the behavior of the building without any soil effect, fixed base model of the same building has been performed as shown in Fig. 4.

Table 2 Elastic stiffness of springs employed in the model

\begin{tabular}{||c||c|c|c|c|c||}
\hline \hline \multirow{2}{*}{$\begin{array}{c}\text { Column } \\
\text { Type }\end{array}$} & \multicolumn{5}{|c||}{ Stiffness Coefficient Ko } \\
\cline { 2 - 6 } & $\begin{array}{c}\text { Trans- } \\
\text { Vertical }\end{array}$ & $\begin{array}{c}\text { Trans- } \\
\text { Horizontal }\end{array}$ & Tortional-Z & Rocking-X & Rocking-Y \\
\hline \hline \multirow{2}{*}{ A } & $5.21 \mathrm{E}+04$ & $4.14 \mathrm{E}+04$ & $4.65 \mathrm{E}+05$ & $3.53 \mathrm{E}+05$ & $3.52 \mathrm{E}+05$ \\
\hline B & $7.39 \mathrm{E}+04$ & $5.88 \mathrm{E}+04$ & $1.46 \mathrm{E}+06$ & $1.48 \mathrm{E}+06$ & $6.88 \mathrm{E}+05$ \\
\hline C & $7.17 \mathrm{E}+04$ & $5.70 \mathrm{E}+04$ & $1.25 \mathrm{E}+06$ & $1.14 \mathrm{E}+06$ & $7.42 \mathrm{E}+05$ \\
\hline D & $1.04 \mathrm{E}+05$ & $8.24 \mathrm{E}+04$ & $4.34 \mathrm{E}+06$ & $4.68 \mathrm{E}+06$ & $1.65 \mathrm{E}+06$ \\
\hline \hline
\end{tabular}

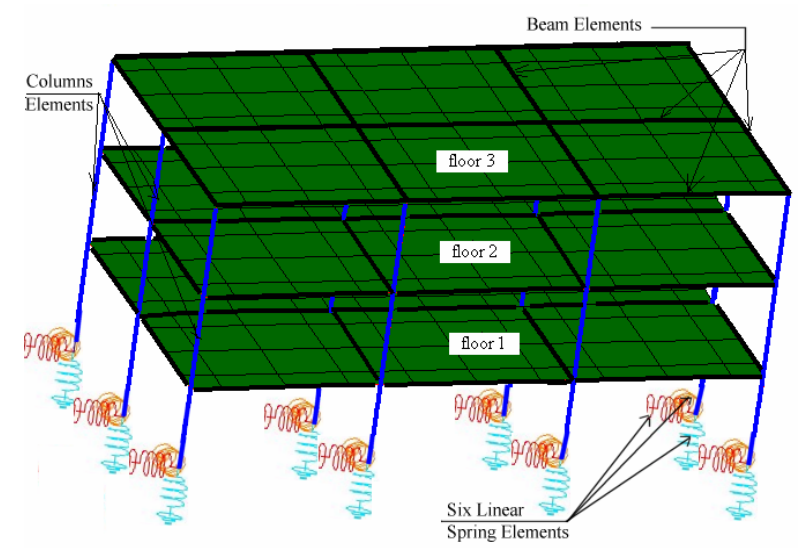

Fig.3 Linear Springs FE Model of 3-Story Building

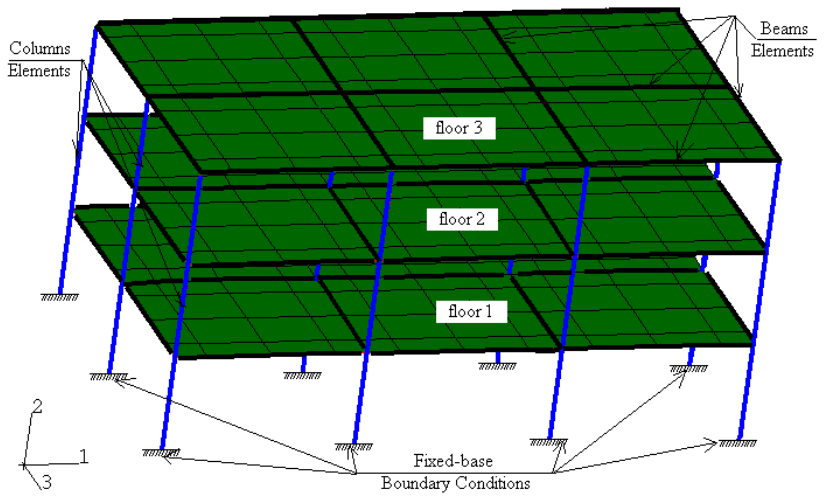

Fig.4 Fixed Base FE Model of 3-Story Building

\section{SEISMIC RESPONSE TIME HISTORY ANALYSIS}


Using the modeling procedures described in the previous section, the four models were excited with a sever earthquake event $(M=7.5)$. The fixed-base and linear springs models were excited with earthquake ground surface motion (Fig. 5). These models were excited at the bottom of the columns nodes. The soil models (linear and non-linear) were excited with earthquake bedrock motion (Fig. 6) at the bottom nodes of the last soil layer. The non-linear soil model fails to converge after $14.1 \mathrm{~s}$ time history indicating possible failure of the model, whereas the other three models complete the $20 \mathrm{sec}$ time history successfully. A comparative study is now presented for these models based on an evaluation of various damage indices including acceleration time history, floors drift ratio, and, moment-curvature behavior of different columns.

\section{ACCELERATION TIME HISTORY}

The time history considers the acceleration response of the system at selected key points. If one of the natural frequencies of the structure is excited by an input motion, the acceleration response could be of a very high magnitude. On the contrary, a low response could indicate effective damping of the input motion by some of the components in the model. Therefore, by a judicious selection of the points at which the time history is viewed, an overall picture of the response of the structure can be obtained.
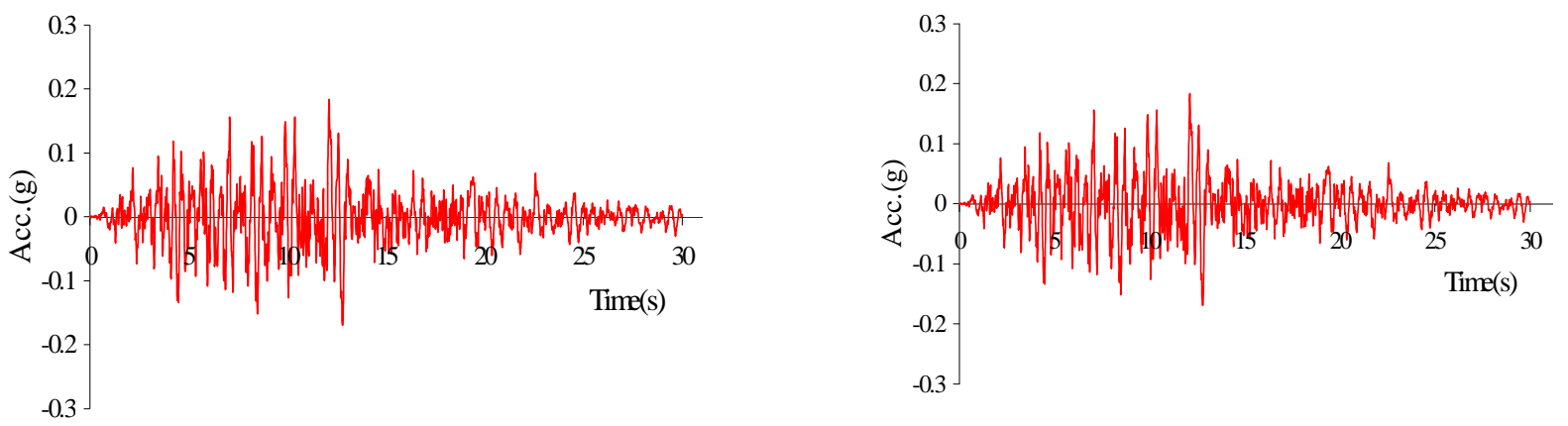

1-Axis and 3-Axis Horizontal motion
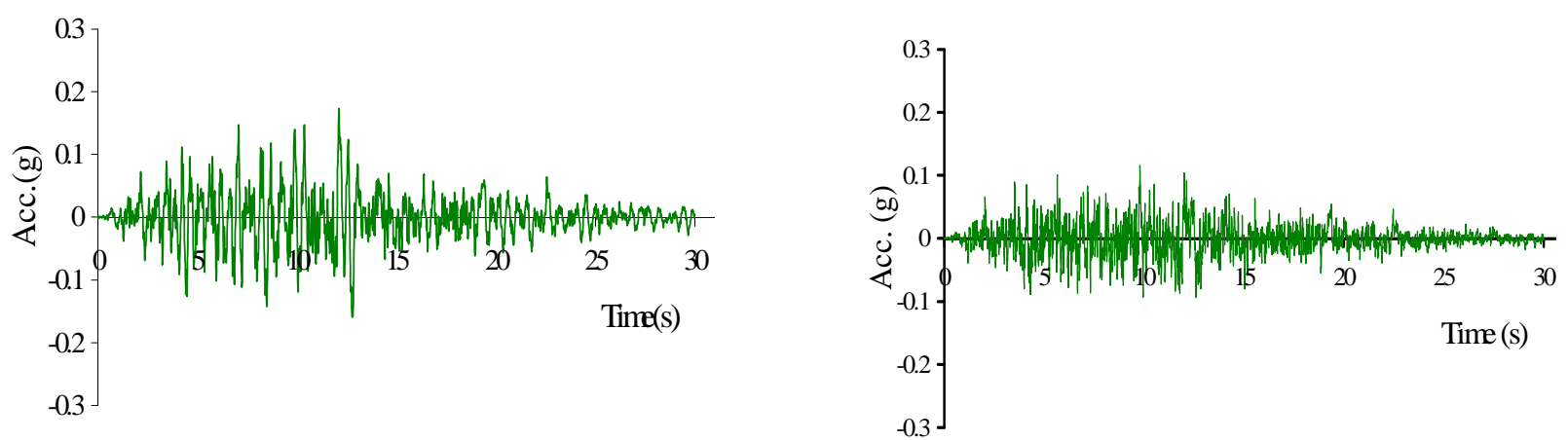

Vertical Motion

Fig. 5 Acceleration time history of input ground motion for fixed-base and linear springs

Fig. 6 Acceleration time history of input ground motion models $(M=7.5)$. for the soil models $(M=7.5)$.

Fig. 7 and Fig. 8 show the computed acceleration response time histories for maximum horizontal and vertical component motions at a selected point for fixed-base and linear SSI models and soil 
models respectively. This selected point corresponds to the center of the top floor slab location and exhibited the largest vertical acceleration during the analysis. The responses of the four models appear to be dominated by the fundamental and low frequency global response modes in the horizontal directions. The vertical amplification is higher than the horizontal ones and related more to localized motions of the floor slab at higher frequency modes. The horizontal accelerations offer damage potential for the columns on the order of $0.3 \mathrm{~g}$ for the fixed-base and linear springs models, $0.5 \mathrm{~g}$ for the linear soil model, and $0.6 \mathrm{~g}$ for non-linear soil model. This represents an amplification ratio of approximately 1.8, 3.2 and, 3.25 for both fixed-base and linear springs models, linear soil model, and non-linear soil one, respectively, with respect to the peak resultant horizontal acceleration of $0.17 \mathrm{~g}$. In other words, the dynamic behaviors of the four models are nearly the same with respect to zero crossings, but there is a considerable difference in the amplitude of the peaks for each model.

\section{FLOOR DRIFT RATIO}

The second criterion used in the damage assessment is the floor drift ratio. The drift ratio for a member is defined as the relative displacement between the two ends of the member divided by its length. This gives more localized indication of the lateral deformation of all the columns at a given floor level. SBCCl code (1994) specifies the maximum acceptable value of the story drift ratio as 0.01 [6]. Fig. 9 presents the horizontal drift ratio in the 1-axis for first floor for the four models. From these figures we can conclude that the dynamic behavior of the four models is nearly the same, with respect to zero crossing but exhibit considerable difference in the amplitude. Again the floor drift ratio of the fixed-base model and linear springs model are nearly the same and the non-linear soil model has the maximum drift ratio.

Also, it is noticed that the response of the linear soil model and non-linear soil model coincide for the first 5 seconds of the record, and then the peak amplitudes of the non-linear soil response start to be higher than the peak amplitude of the linear soil response. This indicates that the nonlinear behavior of the soil starts 5 seconds after the beginning of the analysis. Also, it is clear from the figure that, for fixed-base and linear springs models, the drift ratios of the three floors are less than the code limiting value specified earlier. This indicates that the columns in these models are able to withstand the shaking without significant damage.

On the other hand, the linear soil model drift ratio exceeded the code limiting value in the third floor, axis-1, and the non-linear soil model drift ratio exceeded the code limiting value in axis-1 and axis-3. Drift ratios in excess of this limit indicate significant column damage potential. This potential is best reflected by the more localized index moment-curvature response.

In general, the maximum drift ratios predicted by the soil models were higher than those predicted by the fixed-base and linear spring models. Also, the maximum drift ratio values for all models were predicted by the non-linear soil model. 

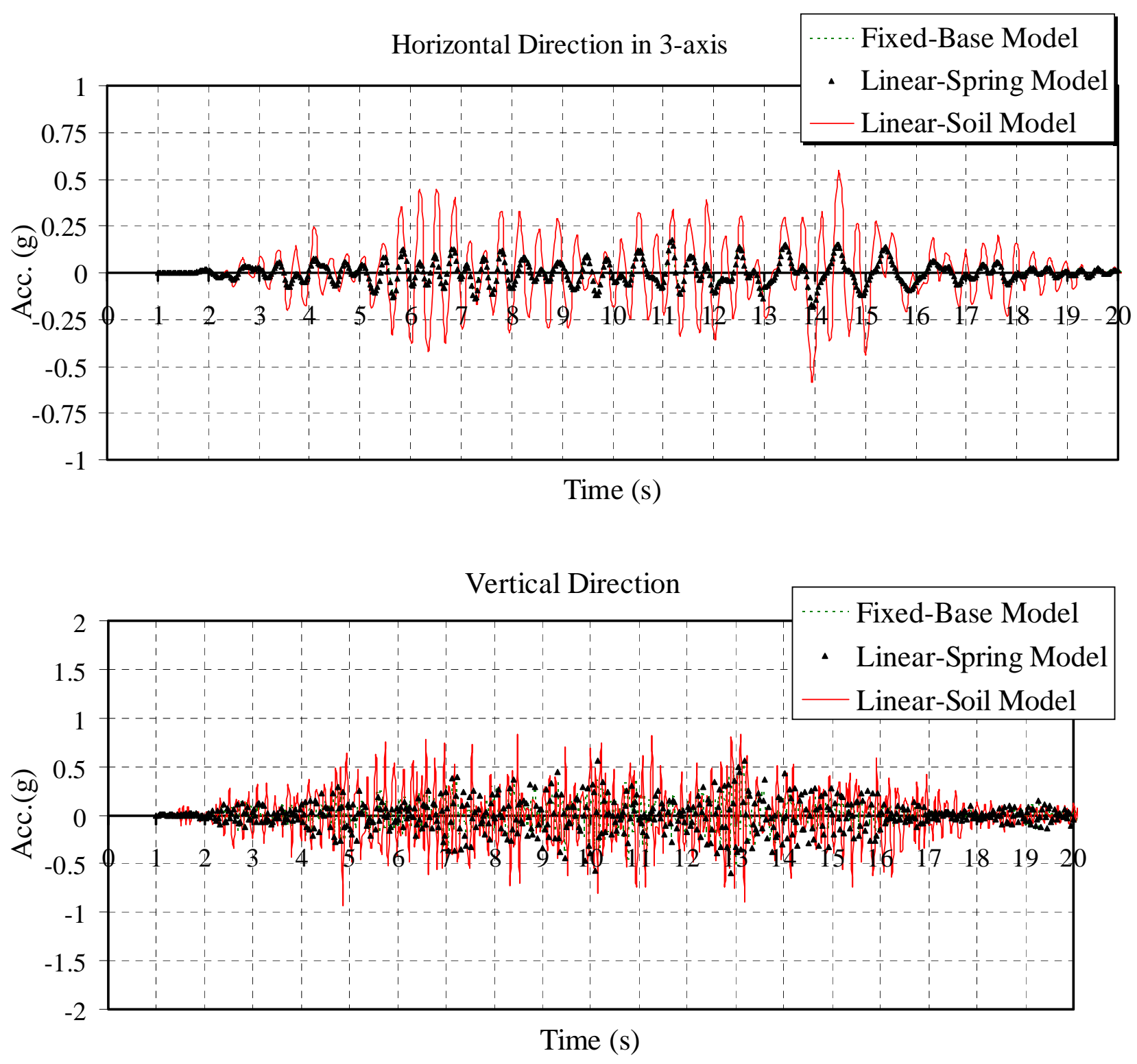

Fig. 7 Acceleration response at the center of the top floor slab. 

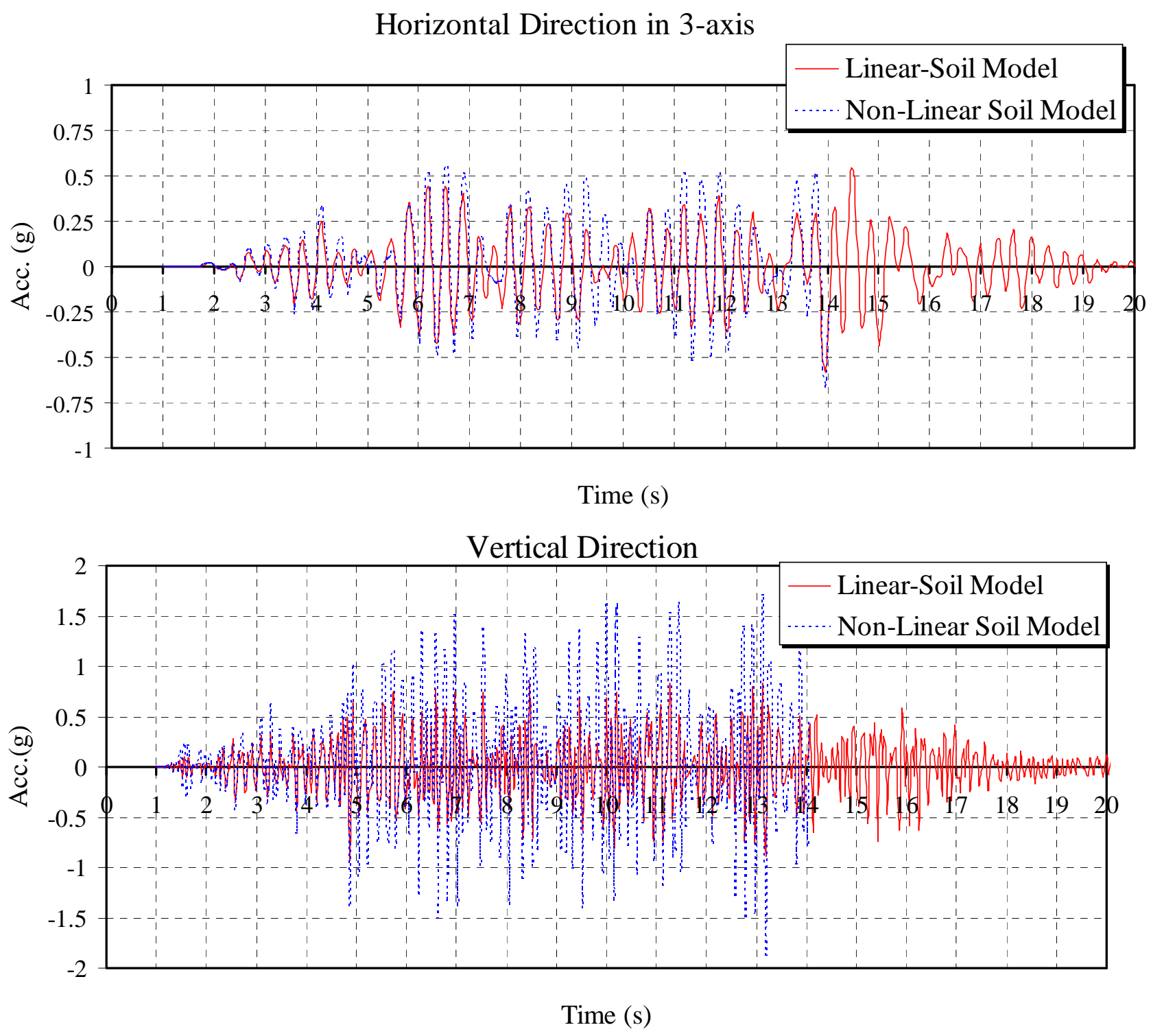

Fig. 8 Acceleration response at the center of the top floor slab. 
First Floor Horizontal Drift Ratio

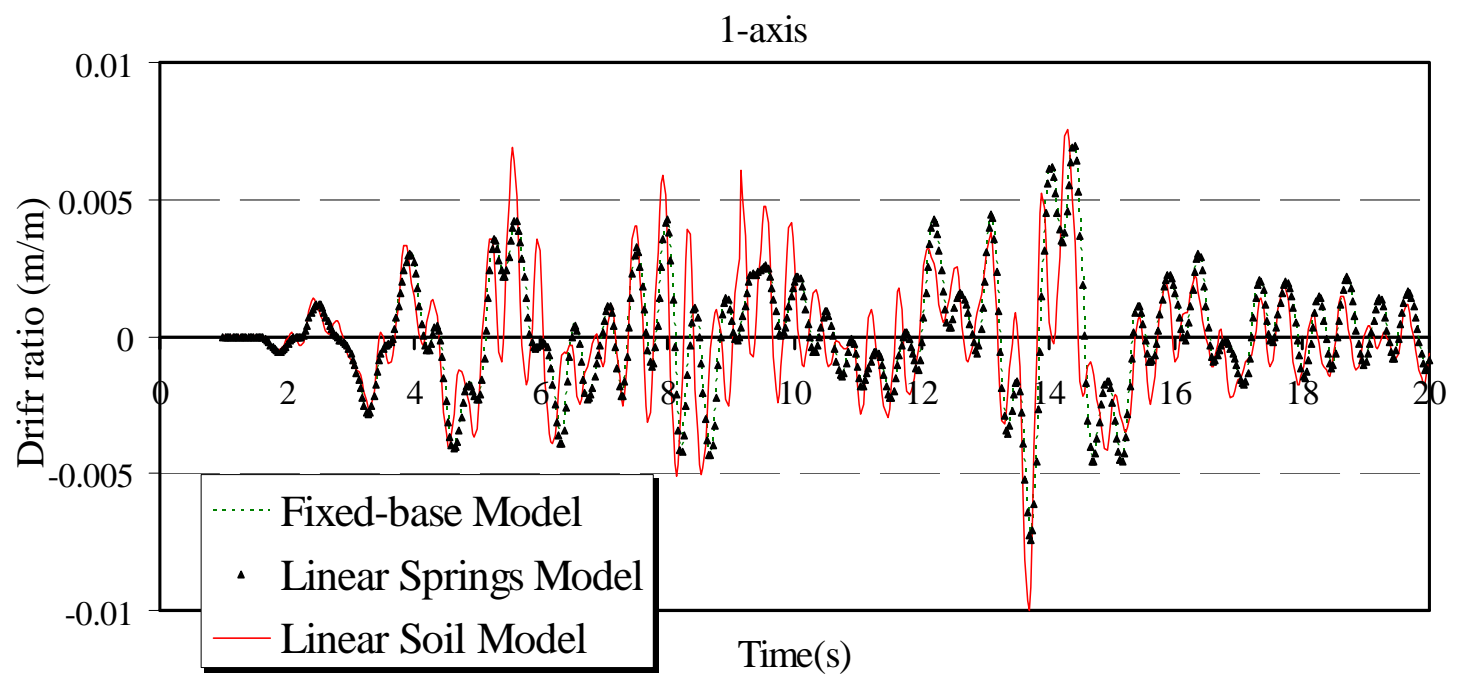

First Floor Horizontal Drift Ratio

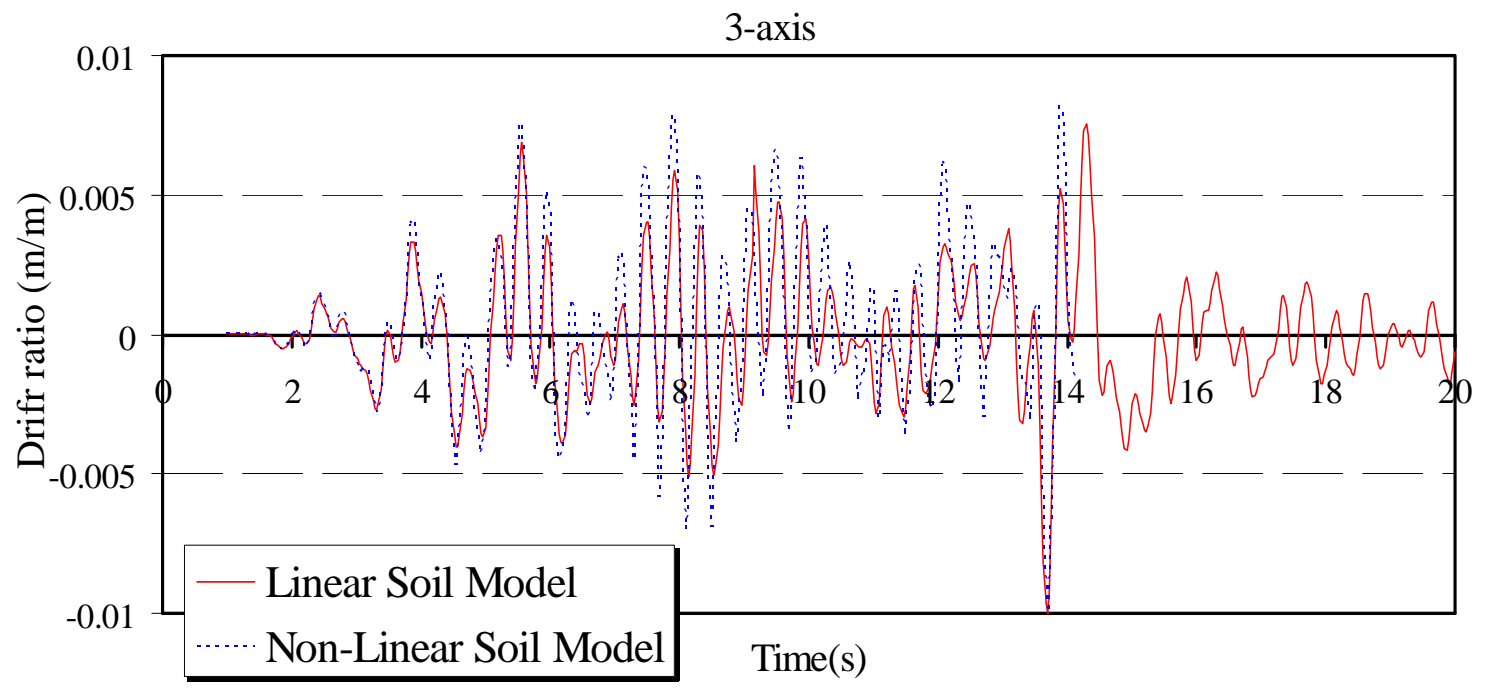

Fig. 9 First floor horizontal drift ratio

\section{MOMENT-CURVATURE HISTORY}

The fourth criterion used to evaluate the modeling procedures is the moment-curvature hysteresis plots. Fig. 10 presents the moment-curvature seismic response of one of the interior columns of 
the building model. It is clear that, a noticeable seismic response is observed in the fixed-base and linear spring models, and the yield moment is exceeded in the 3-axis of the column. For the linear soil model, many major hysteresis cycles are noticed in 1-axis. However, the yield moment is exceeded in the 1-axis and 3-axis of the column. The seismic response of the non-linear soil model provides many major hysteresis cycles in both axes. The yield moment is exceeded in both axes by a considerable value. While the model allows for a small residual moment capacity after the formation of a plastic hinge, the loading apparently demanded large curvatures in excess of the yield curvature. Based on the inability to converge to a solution, the non-linear soil model was not able to distribute the load. Thus, failure or collapse is assumed to have taken place. It is noticed that the highest moment values were determined by the non-linear soil model, then the linear soil model and, at last, the fixed-base and linear springs models. Also, in case of fixed-base and linear springs model, the first floor is subjected to the highest moment value, then, second floor and at last, third floor and, conversely, for the soil models. This is due to the additional rocking moment, increased with the building height, caused by the vertical stress difference between the soil elements underneath the footing edges in the soil models.

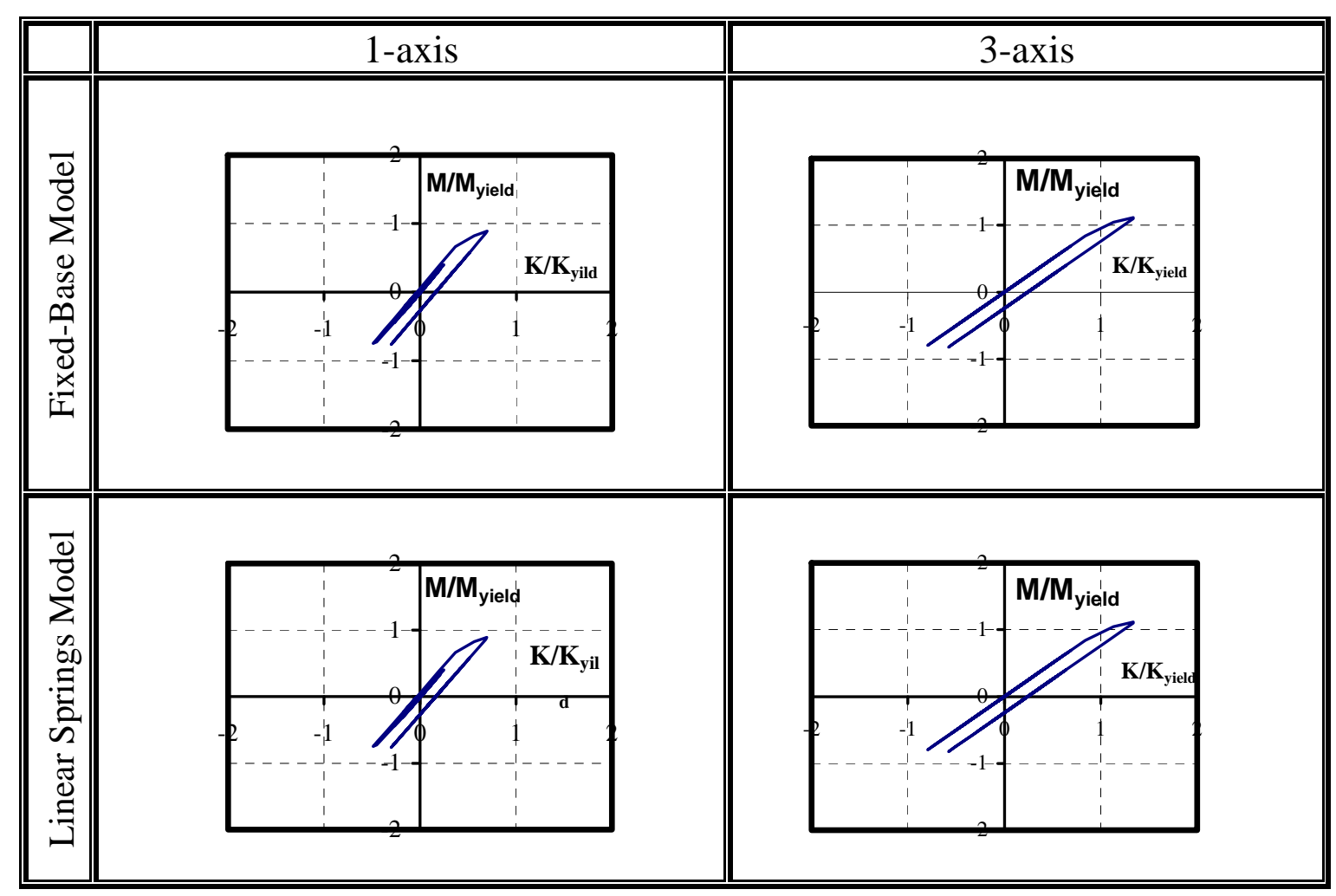




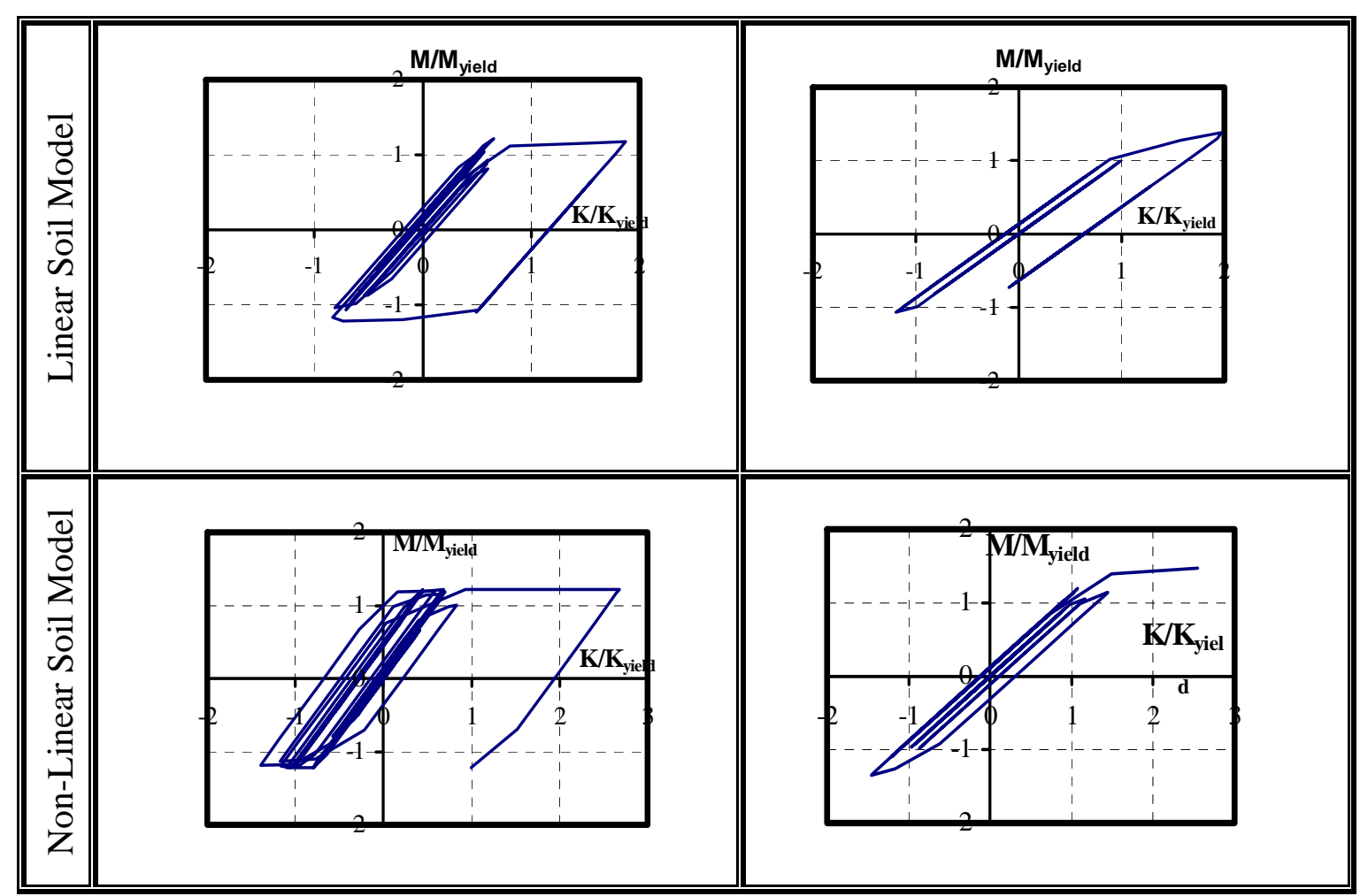

Fig. 10 Moment -Curvature for one of the interior column.

\section{CONCLUSIONS}

A computational procedure for modeling soil-structure interaction has been proposed based on wave propagation studies of footing type problems with large scale finite element models of building systems in mind where mesh design is a critical aspect of the analysis. The effective use of the procedure is demonstrated for a 3-D model of a typical building system. The proposed procedure includes radiation damping through infinite elements, contact surfaces at footing / soil interfaces, and local nonlinear material response of the soil around the footing. These features are only approximately incorporated in conventional analysis with linear discrete springs. Also, for the simulated acceleration time histories, the response of the fixed-base and linear springs models were nearly the same. On the other hand, the soil models responses were higher by $45 \%$ in the nonlinear soil model and $40 \%$ in the linear soil model. For the inter-story drift ratio, the fixed-base and linear springs responses predict drift ratios less than the code limiting value for all three floors, which indicates that the columns in these models are able to withstand the shaking without significant damage. On the other hand, the linear soil model drift ratio passed the code limiting value in the third floor in the short direction of the building frame and the nonlinear soil model drift ratio passed the code limiting value in both frame directions. The more realistic soil models predict more column damage more than do the fixed-base and linear springs models highlighting the enhanced insight possible using a nonlinear soil model. The linear springs model seismic response was much like the fixed-base model response, which did not predict significant damage or collapse, as did the more realistic soil models. This indicates that the linear springs in 
this model whose constants were computed according to the FEMA273 guidelines were inadequate in the case analyzed. The linear springs do not allow for softening effects of local soil weakening beneath the foundation elements, nor do they allow for radiation damping.

\section{REFERENCES}

1) Wolf, J. P., and Song, C., “Finite Element Modeling of Unbounded, Media”, John Wiley \& Sons, 1989.

2) Ismail, I. M. and Mullen, C. L., "Primary Investigation of using Infinite Elements modeling Transmitting Boundary for Soil-Structure Interaction Dynamic Problems”, Tenth International Colloquium on Structural and Geotechnical Engineering $\left(10^{\text {th }}\right.$ ICSGE) Ain Shames University 2003.

3) Hibbitt, K. S., “ABAQUS/Standard User’s Manual, Version 5.6”, Providence, Rhode Island, 1996.

4) “Standard building Code”, Southern Building Code Congress International, 1994.

5) “NEHRP Guidelines for the Seismic Rehabilitation of Buildings”, FEMA 273, Federal Emergency Management Agency, 1997.

6) Swann, C. T., Mullen, C. L., Hackett, R. M., Stewart, R., and Lutken, C. "Seismic Vulnerability Assessment of Selected Structures and Facilities on Campus of the University of Mississippi, A mitigation Model for University”, Final Report, Mississippi Emergency Management Agency,1999.

7) Ismail, I. M. and Mullen, C. L., "Soil-Structure Interaction Issues For 3-D Computational Simulation Of Nonlinear Seismic Response”, EM2000 ASCE national meeting, Austin, Texas 2000.

8) Al-Homoud, A. S., “Evaluating Title of Gravity Retaining Walls during Earthquakes”, Ph.D. Thesis, Department of Civil Engineering, Massachuetts Institute of Technology, Cambridge, USA, 1990.

9) Lynn, P. P. and Hadid, H. A., “Infinite Elements With $1 / \mathrm{r}^{\mathrm{n}}$ Type Decay”, International Journal For Numerical Methods In Engineering, Vol. 17, pp.347-355, 1981. 